\title{
The Readiness of the Teacher Training Institution in Preparing Teacher Competencies
}

\author{
Dian Artha Kusumaningtyas ${ }^{1, *}$, Jumadi ${ }^{2}$, Edi Istiyono ${ }^{2}$, Dwi Sulisworo ${ }^{3}$ \\ ${ }^{1}$ Education Sciences, Graduate Program, Yogyakarta State University, Indonesia \\ ${ }^{2}$ Department of Physics Education, Yogyakarta State University, Indonesia \\ ${ }^{3}$ Department of Physics Education, Ahmad Dahlan University, Indonesia
}

Received May 17, 2020; Revised June 27, 2020; Accepted July 20, 2020

Copyright $\mathrm{O} 2020$ by authors, all rights reserved. Authors agree that this article remains permanently open access under the terms of the Creative Commons Attribution License 4.0 International License

\begin{abstract}
Teacher quality determines the process of education reform. MOEC of Indonesia has prepared various schemes to achieve this quality. MOEC expects study programs held at higher education to meet the competencies of prospective teachers in four aspects, namely professional, pedagogy, social, and personality. This study is to describe the achievement of competence level as a teacher in the physics education study program. The method used is a survey method for physics education students, with 50 students participating. Competency measurement uses the test instrument consisting of four aspects, namely professional (65 items), pedagogy (45 items), social (40 items), and personality (40 items). The instrument refers to an evaluation conducted by National Education Standards Agency. It was analyzed using Two-way ANOVA to see the effect of gender and learning experiences. The results show that gender does not affect competence. Instead, the learning experience influences on competence. Average score of the ability of the students is lower than the limit specified teacher competency requirements MOEC. This result means that professional, pedagogical, social, and personality competencies are not yet the focus of teacher training institutions. The learning process experienced by prospective teachers (students) has not been able to improve competence significantly to achieve the MOEC's standard. This result implies that the study program needs to evaluate the curriculum and the learning process so that graduates can achieve quality teachers.
\end{abstract}

Keywords Education Reforms, Higher Education, Physics Education, Physics Teacher, Teacher Competency, Teacher Training

\section{Introduction}

The quality of teaching is one of the variables that determine the competitiveness of a country. Many countries initiate and actualize changes in instructions to build quality national competitiveness maintained through high-quality human assets [1,2]. One of the Indonesian government's efforts through the Instruction and Culture Service (MOEC) is to advance instructors' quality through various plans. This arrangement is in line with multiple countries' provisions for changes in educators [3]. The government anticipates that standardization of quality through teacher certification will empower students to move up to instruction in various districts $[4,5]$. Thinking about planning high-quality instructors, counting people in instructors preparing to teach, finally essential [6-8].

There are several considerations regarding the relationship between getting to instructor quality and student achievement, counting them on the changes in Indonesia [9]. Some reflections emerge that the more critical gap is to reach qualified instructors and student achievement $[2,10]$. Another consideration regarding the relationship between instructor compensation and national performance appears that countries with a better salary than experienced instructors tend to have higher national instruction achievement. However, the standard national compensation for new graduate instructors has no relationship with public performance [11,12]. Even though payment is not only one of the factors supporting the quality of instructors, it must guarantee the government's funding force in building teacher competencies $[13,14]$. This performance will support the policy of improving teacher quality through various regulations $[15,16]$. The availability of national policies on teacher quality tends to have a significant influence on national student achievement [17-19]. 
In Indonesia, improving the quality of educators is inseparable from the modern MOEC program called 'Sekolah Merdeka' (freedom to learn). The program runs in 2020. With the number of instructors reaching 3.1 million (see http://statistik.data.kemdikbud.go.id/), it is not easy to run this program. One of the essential components in advancing instructor quality is the standardization of educator calls. Since 2017, the Indonesian government has adopted a certification approach. The government supports this program by motivating power arrangements for instructors who meet proficient abilities. This program victory is about expanding the accessibility of skilled instructors who can advance successor achievements [14,20,21].

Together with improving the administration of educators in Indonesia, currently, graduates of non-teacher teaching programs can become instructors (based on an official letter issued by the Directorate of Learning and Teaching Problems and the Directorate for Improving Educators of Essential Instructors). However, graduates of teaching programs for educators are still a remarkable asset for prospective educators. The program ponders instruction in general under the administration of teaching staff preparing and training in teaching higher education. The position of material science instructors in high schools will be, among other things, from graduates of the material science instructor program. Planning students in the science education study program at the higher education as a prospective science instructor becomes the basis for forming competency.

Based on Law Number 14, 2005 concerning Instructors and Teachers, article 10 paragraph (1) states that educator competencies include competent competencies, teaching method competencies, social competencies, and identity competencies obtained through qualified teaching. Proficient competence is the capacity of educators in the authority of learning material broadly and deeply. It also relates to the predict the influence of the substance of educational programs in schools, relevant content, and logical structure and strategy. Competence of learning methods is the capacity to get students, learning plans and implementation, assessment of learning outcomes, increasing students to actualize their possibilities. Social competence is the capacity of teachers to communicate and actively connect with students, instructive workforce, guardians or gatekeepers of students, and the surrounding community. Personality competence is an individual capacity that reflects solid, steady, developing, intelligent, and charismatic.

Based on this regulation, the Ministry of Education and Culture developed various instruments to measure competence. At the level of the study program, preparing prospective teachers (including Physics teachers) is very important. This preparation includes mapping of competencies and studies related to the readiness of institutions to develop the skills of prospective teachers (students). This skill is the basis for developing a curriculum and learning systems. MOEC carries out various plans in various forms to improve teacher competency. The government is aware that the availability of qualified teachers is one of the critical pillars in improving the nation's competitiveness. However, society will not enjoy the results soon.

This research is to support MOEC's policies aimed to figure out the effect of gender and learning experience on four teacher competencies. The results of this study will form the basis of study program management policies. The policy is the training of prospective teachers, especially on improving curriculum and learning processes that focus on competencies as potential teachers.

\section{Methods}

\subsection{Context}

This research was conducted at a higher education institution conducting Physics teacher candidates through a study program in Yogyakarta, Indonesia. This study program prepares students to become teachers in junior or senior/vocational high school. In Indonesia, there are two ways to become a certified teacher. First, the Ministry of Education and Culture provides opportunities for teachers who have worked (on-job) to attend the certification program. The program includes knowledge acquisition activities through online learning, workshops, peer teaching, and internships for three months. The second is for prospective teachers (who have not taught). They must attend the Teacher Education Program for one year. Thus, alumni of Physics education study programs do not automatically have certification as Physics teachers. (based on an official letter from the Directorate of Basic Education Teacher Development No. 7713/ B.3/ GT/ 2019). Participants in this study were 50 students with gender characteristics (7 male students; Female; 43 students) and the ongoing semester (2nd-semester: 24 students; 6th-semester: 26 students).

\subsection{Instruments}

The competency measurement instruments for prospective physics teachers include four aspects, namely professional (DVAR1, 65 items), pedagogy (DVAR2, 45 items), social (DVAR3, 40 items), personality (DVAR4, 40 items). Measurement of these aspects uses a multiple-choice test with five choices, with only one correct answer. The score is 1 for each correct answer. The development of the instrument refers to an evaluation conducted by BSNP (National Education Standards Agency). Table 1 shows the Core Competencies for each aspect. 
Table 1. List of Core Competencies

\begin{tabular}{|c|c|c|}
\hline No & Aspects & Core Competencies \\
\hline \multirow{3}{*}{1} & \multirow{3}{*}{$\begin{array}{l}\text { Professional } \\
\text { (DVAR1) }\end{array}$} & 1. Mastering the material, structure, concepts, and scientific mindset that supports the subjects \\
\hline & & 2. Developing a matter of learning which of teaching is creative \\
\hline & & 3. Utilizing information and communication technology to develop themselves \\
\hline \multirow{3}{*}{2} & \multirow{3}{*}{$\begin{array}{l}\text { Pedagogy } \\
\text { (DVAR2) }\end{array}$} & 4. $\quad$ Planning learning \\
\hline & & 5. Carry out learning \\
\hline & & 6. $\quad$ Assessing and evaluating learning \\
\hline \multirow{6}{*}{3} & \multirow{6}{*}{ Social (DVAR3) } & $\begin{array}{l}\text { 7. Demonstrate a love for the motherland and nationalism by contributing to community and state life, } \\
\text { obeying the law, and discipline }\end{array}$ \\
\hline & & $\begin{array}{l}\text { 8. Being inclusive and appreciate the diversity of religion, race, condition of physical, the background } \\
\text { behind the family, the status of the social economy, and considering the differences in gender. }\end{array}$ \\
\hline & & $\begin{array}{l}\text { 9. Communicate and interact in an effective, empathetic, and polite with students, fellow teachers, staff } \\
\text { education, the elderly, and people who constituted the sensitivity of the social and caring }\end{array}$ \\
\hline & & $\begin{array}{l}\text { 10. Work together and adapt to the participant students, colleagues, staff education, parents, similar } \\
\text { community occupations and professions others and society as oral or form another that has a diversity of } \\
\text { socio-cultural }\end{array}$ \\
\hline & & $\begin{array}{l}\text { 11. Demonstrate a love for the motherland and nationalism by contributing to community and state life, } \\
\text { obeying the law, and discipline }\end{array}$ \\
\hline & & $\begin{array}{l}\text { 12. Communicate and interact in an effective, empathetic, and polite with students, fellow teachers, staff } \\
\text { education, the elderly, and people who constituted the sensitivity of social and caring others who have a } \\
\text { diversity of socio-cultural }\end{array}$ \\
\hline \multirow{7}{*}{4} & \multirow{7}{*}{$\begin{array}{l}\text { Personality } \\
\text { (DVAR4) }\end{array}$} & 13. Pious to God Yang Maha Esa and able to demonstrate a religious attitude \\
\hline & & 14. Upholding the high value of humanity in running the task based on religion, morals, and ethics \\
\hline & & 15. Internalize academic values, norms, and ethics \\
\hline & & 16. Shows the attitude of responsibility on work in the field of expertise is independent. \\
\hline & & 17. Internalize the spirit of independence, struggle, and entrepreneurship \\
\hline & & 18. Demonstrating behavior that is in line with the Indonesian teacher's code of ethics \\
\hline & & $\begin{array}{l}\text { 19. Have sincerity, commitment, the sincerity of the heart to develop the attitudes, values, and the ability of } \\
\text { the participant students based on the importance of local wisdom and moral noble. }\end{array}$ \\
\hline
\end{tabular}

\subsection{Analysis Technique}

This study uses an ex-post facto research approach. Statistical analysis techniques are qualitative analysis based on test data for each DVAR1, DVAR2, DVAR3, and DVAR4. The subsequent review will employ descriptive statistical analysis to determine the average and standard deviations of each competency variable for each independent variable, gender (IDVAR1) and experience or study duration (IDVAR2). The average difference test (t-test) was conducted with Two-way ANOVA to determine the effect of IDVAR1 and IDVAR2 on competence (DVAR). Descriptive data results are also used to determine the interaction between IDVAR1 and IDVAR2 on DVAR. The margin of error (p-value) used is 0.05 .

\section{Result}

\subsection{Descriptive}

The results of data collection for each DVAR1, DVAR2, DVAR3, and DVAR4 can be used to see the data trends of each component or factor. Table 2 shows these trends.
Table 2. Correlation between variables

\begin{tabular}{|l|c|c|c|c|c|c|}
\multirow{2}{*}{ Factors } & \multirow{2}{*}{ Means } & $\begin{array}{c}\text { Standard } \\
\text { Deviation }\end{array}$ & \multicolumn{5}{|c|}{ Correlations } \\
\cline { 4 - 7 } & & DVAR1 & DVAR2 & DVAR3 & DVAR4 \\
\hline DVAR2 & 18.4000 & 3.84389 & 1 & & & \\
DVAR3 & 18.4000 & 3,51092 & .181 & $.366^{* *}$ & 1 & \\
\hline DVAR4 & 22.8571 & 3,71612 & -.039 & $.337^{*}$ & $.310^{*}$ & 1 \\
\hline
\end{tabular}

**. Correlation is significant at the 0.01 level (2-tailed).

* Correlation is significant at the 0.05 level (2-tailed).

As stated in the method, each variable has a maximum score (DVAR1: 65 points; DVAR2: 45 points; DVAR3: 40 points; and DVAR4: 40 points). Table 1 shows that each variable still reached a shallow score (DVAR1: 18.40 of 65 or $28.31 \%$; DVAR2: 20.04 of 45 or $44.53 \%$; DVAR3: 18.40 of 40 or $46.00 \%$; and DVAR4: 22.86 of 40 or $57.15 \%$ ). Standard deviations tend to lead to little achievement compared to the competency graduation rate of $76 \%$. Table 3 shows detailed data related to participant descriptive based on IDVAR1 and IDVAR2.

While the DVAR value is the sum of DVAR1, DVAR2, DVAR3, and DVAR4 scores. Besides, Figure 1 explains the distribution of competency achievements (DVAR) for each component. 


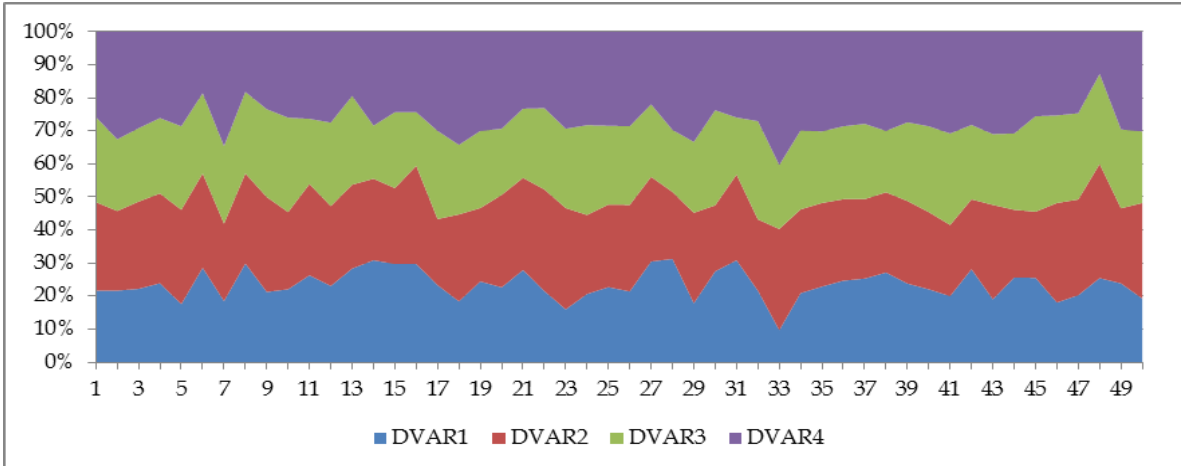

Figure 1. Competencies profile of students

Figure 1 shows that the proportion of DVAR1 to DVAR4 for DVAR tends to be the same. Table 3 shows the descriptive data based on IDVAR1 and IDVAR2. This table can be seen the trend of the influence of IDVAR1 and IDVAR2.

Table 3. Descriptive Statistics

\begin{tabular}{|c|c|c|c|c|}
\hline \multicolumn{5}{|c|}{ Dependent Variable: DVAR } \\
\hline IDVAR1 & IDVAR2 & Mean & Std. Deviation & $\mathrm{N}$ \\
\hline \multirow{3}{*}{ Male } & 2nd-semester & 63.0000 & 1.41421 & 2 \\
\hline & 6th-semester & 87.8000 & 8.67179 & 5 \\
\hline & Total & 80.7143 & 14.03228 & 7 \\
\hline \multirow{3}{*}{ Female } & 2nd-semester & 78.3182 & 8.02607 & 22 \\
\hline & 6th-semester & 77.6190 & 9.63575 & 21 \\
\hline & Total & 77.9767 & 8.494912 & 43 \\
\hline \multirow{3}{*}{ Total } & 2nd-semester & 77.0417 & 8.80948 & 24 \\
\hline & 6th-semester & 79.5769 & 10.15154 & 26 \\
\hline & Total & 78.300 & 9.52068 & 50 \\
\hline
\end{tabular}

This data shows that IDVAR2 can improve competence (DVAR) from 77.04 to 79.58. Further analysis with variance analysis (Two-way ANOVA) is employed to see whether the difference in competency scores between the 2nd semester and 6th semester is significant. This analysis is also to see the effect of IDVAR1 or IDVAR2 on DVAR.

\subsection{Effects of IDVAR1 and IDVAR2}

Analysis of variance (Two-way ANOVA) was used with an alpha of 0.05 to see the effect of IDVAR1 and IDVAR2. Table 4 figures out the results of this analysis. This table explains whether IDVAR1 or IDVAR2 affects the teacher competence to students.

Table 4 shows, IDVAR1 does not affect DVAR (Sig. $=.512 ; \mathrm{p}$-value $=0.05)$. Conversely, IDVAR2 affects teacher competency $(\mathrm{Sig} .=.003 ; \mathrm{p}$-value $=0.05)$. However, IDVAR1 and IDVAR2 together affect teacher competency (Sig. $=.002 ; \mathrm{p}$-value $=0.05$ ). These results indicate that the learning process (IDVAR2) has effectively increased competency as a teacher candidate when it assumed that competencies in 6th-semester are skill accumulation built since the first semester.

\subsection{Interaction between IDVAR1 and IDVAR2}

Now, Two-way ANOVA is applied to find the interaction of IDVAR1 and IDVAR2. In this analysis, using descriptive data in Table 2, it can be seen the interaction between IDVAR1 and IDVAR2. Figure 2 shows the results of data processing.

Figure 2 explains the analyst that the interaction between IDVAR1 and IDVAR2 occurs. These results indicate that DVAR, male teacher candidates (students) have a higher score in 6th-semester (87.80) compared to 2nd-semester (63.00). Conversely, female teacher candidates (students) have higher scores in 2nd-semester (78.32) than 6th-semester (77.62). These different achievements lead to an interaction between two variables, IDVAR1 and IDVAR2. 


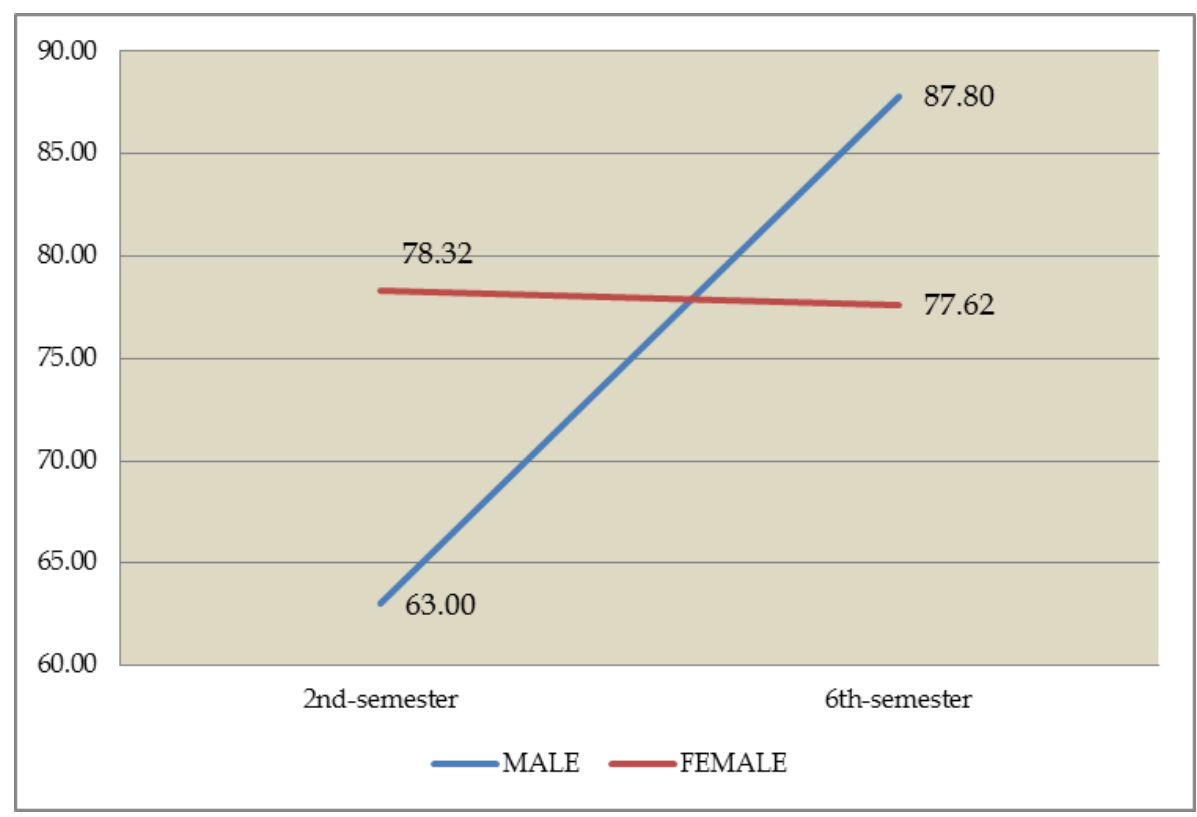

Figure 2. Interaction between IDVAR1 and IDVAR2

Table 4. Tests of Between-Subjects Effects

Dependent Variable: DVAR

\begin{tabular}{|c|c|c|c|c|c|}
\hline Source & Type III Sum of Squares & df & Mean Square & F & 4,055 \\
\hline Corrected Model & $928,995^{\text {a }}$ & 3 & 309,665 & 1553,667 & .012 \\
\hline Intercept & 118636,819 & 1 & 118636,819 & .436 & .512 \\
\hline IDVAR1 & 33,277 & 1 & 33,277 & 9,592 & .003 \\
\hline IDVAR2 & 732,406 & 1 & 732,406 & 10,737 & .002 \\
\hline IDVAR1 * IDVAR2 & 819,856 & 1 & 819,856 & & \\
\hline Error & 3512,525 & 46 & 76,359 & & \\
\hline Total & 311456,000 & 50 & & & \\
\hline
\end{tabular}

a. R Squared $=.209$ (Adjusted R Squared $=.158$ )

b. Computed using alpha $=.05$

\section{Discussions}

A teacher is an essential figure in the education system in Indonesia. The role and potential of teachers greatly influence the achievement of the nation's short-term and long-term education. A teacher is an essential motivator for student success in the short term, as is an academic success [22]. And also, in the future, such as their presence in higher education and the labor market, which is the motor of development [23]. Preparing prospective teachers through teacher training institutions is an integral part of the process of developing quality teachers. The analysis of the data calculates the different test results (t-test) of the average competence between 2nd-semester and 6 th-semester. It seems that the learning process significantly increases competency. However, these results are still not satisfactory in terms of learning effectiveness. Because the average competency score
(DVAR) is always lower than the minimum score requirement (passing score) of the teacher competency determined by the Ministry of Education and Culture.

Other results related to gender (IDVAR1) show that this variable does not affect competence (DVAR). In other words, the learning process in the study program has the same effect on gender. In developing the curriculum and learning process, study programs do not need to place different emphasis on gender differences because the achievement of competencies tends to be similar.

After performing the statistical data analysis, the researchers pass interviews with students in semester 2nd-semester and 6th-semester. This interview was to explore why competency scores as prospective teachers are still low. There are four questions raised, namely:

1. Do students understand teacher competencies?

2. If you understand, try to explain the competencies!

3. Does the lecturer teach this competency in lectures? 


\section{What courses taught teacher competencies?}

The respondents are students $(3$ students of 2nd-semester, and 3 students of 6th-semester) selected randomly. From their answer, it tends that between both student groups give similar answers in explaining competence. The similarity of the answers shows that the learning experience has not changed understanding significantly yet. Besides, when viewed from answers that tend to be less profound. The difference was only reflected when mentioning courses that teach about teacher competency. With this result, the study program manager needs to re-evaluate the internalization process of teacher competence in college students.

A more detailed analysis of each factor results is as follows:

\subsection{Professional Competence}

The mean of the professional factor (DVAR1) is 18.4 or 23.31 out of 100 . However, the average score of professional competence is lower than the standard set by the Ministry of Education and Culture, so the study program needs to develop a better learning environment. They expect this development to increase the score to exceed the minimum requirements. The study program must carry out this development since the first semester considering the score in the second semester is also low so that the acquisition between semesters should be facilitated in stages. Professional competence is the mastery of learning material, curriculum content, and mastery of scientific materials and methodologies. With this definition, there are specializations related to professional aspects. This aspect emphasizes the mastery of scientific subjects. Mastery of scientific concepts becomes a medium for students to achieve many abilities. The ability is to understand natural phenomena, solve unclear problems, think critically, and be creative in discovering new things in students' lives. In the physics learning process, students not only gain knowledge as a learning effect but also get other results. Students will form attitudes and behaviors as a parenting effect [24,25].

\subsection{Pedagogical Competence}

The mean of the pedagogical factor (DVAR2) is 20.04 or 44.53 out of 100 . It means that the study program still needs to find a more appropriate strategy so that this competency can reach the graduation level determined by the Ministry of Education and Culture. Pedagogical competence is the ability to understand students, plan and implement learning, evaluate learning outcomes, and develop students to actualize all their potential. With this pedagogical competence, teachers should have to balance the knowledge gained by students and the skills acquired by students for survival. A curriculum developed by balancing conceptual knowledge and skills development is vital for a teacher [26]. A study conducted by [27] found that even superior students could not fully understand the concepts. When presented with non-routine problems, students cannot apply the knowledge they have learned to solve problems.

Reference [28] stated that concept-based teaching has a better effect on increasing student understanding without sacrificing procedural skills. This finding shows the importance of using appropriate learning strategies to master certain concepts. Concept mastery activities by students need to be supported by the teacher's ability from planning to evaluation properly. In current learning, approaches that emphasize student-centered learning need to be adopted by teachers in learning physics that respects students. With this competency, teachers can allow students to improve their abilities in finding new methods and strategies in solving physics problems. One of the reasons students' poor conceptual understanding is the tendency of science teachers to rely on teaching methods or plans that are not effective in improving scientific knowledge [29].

\subsection{Social Competence}

The mean of the social factor (DVAR3) is 18.40 or 46.00 out of 100 . These results are also lower than the requirement. Then, the study program needs to review the curriculum and learning process carried out because the social competency score is still shallow. Social competence is the ability of teachers to communicate and interact effectively with students, education staff, parents or guardians of students, and surrounding communities. This competency places the teacher as part of a wider community. A teacher is a community member who makes a positive contribution to the environment, not only at school.

Teachers can help in developing the community by contributing their knowledge and expertise to the community. Teachers have an essential role in teaching new lessons in solving problems in society [30]. The teacher can do this activity even outside the classroom. To develop these competencies, teachers need to have the ability to communicate and interact in society.

\subsection{Personality Competence}

The mean of the personality factor is 22.87 or 57.14 out of 100 , the highest score among others but still lower than expectation. Therefore, the study program needs to give more emphasis on developing this competency. With a good learning program related to personality development since the first semester, this aspect may not develop again during the learning process. However, given the average score from this aspect, it is still shallow. This result means learning is out of properly, or students do not complete their experiences. 
Personality competence is personal competence that reflects a distinctive personality and noble character. Personality describes the unique psychological qualities influencing an individual's behavior, thought patterns, and feelings in various situations and times [31,32]. A teacher has an important role to be a model, inspiration, and guidance for others [29]. Research findings show that a teacher's personality influences student efficacy but does not affect learning achievement [33]]. It also influences student empowerment [34]. These results emphasize that a good personality will change student behavior through the role models shown by the teacher.

The difference in personality scores in this study supports studies conducted in longitudinal studies. The study found that personal changes in their personality levels and changes in personality traits might occur early in adulthood [35]. These results can explain that students seek and benefit from people who are similar to them in life phases, including personality matches between students and teachers [36].

\section{Conclusions}

The results indicate that gender does not affect competence. At the same time, experience influences competence. Gender and experience together affect competence. There is an interaction between Gender and Semester in all aspects of teacher competence, except pedagogical competence. In general, male teacher candidates in 6th-semester have higher ability than students in 2nd-semester. This phenomenon is slightly different from female students, so the interaction of the two variables occurs. There is no effect of gender on student competency. However, on the contrary, the duration of the study influences student competence. This explanation means that professional, pedagogical, social, and personality competencies are not yet the focus of teacher training institutions. The learning process experienced by prospective teachers (students) has not been able to improve competence significantly. The implication of the research results shows that the learning process in the physics study program has not been running effectively to build student competence. This result takes into account the average score of competence lower than the passing score determined by the Ministry of Education and Culture. As a study program that prepares prospective teachers, these results become the basis for curriculum improvement and the learning process that are more focused on competency as a prospective physics teacher.

\section{Acknowledgments}

Physics Education Department of Ahmad Dahlan University has supported kindly on data collection and physics education student interaction during research.

\section{REFERENCES}

[1] Akiba M. Teacher license renewal policy in Japan. In Teacher reforms around the world: Implementations and outcomes (pp. 123-146). 2013. Emerald Group Publishing Limited.

[2] Akiba M \& Liang G. Teacher Qualification and Achievement Gap: A Cross-National Analysis of 50 Countries. In Closing the Achievement Gap from an International Perspective (pp. 21-40). 2014. Springer Netherlands.

[3] Chapman DW, Snyder CW \& Burchfield SA. Teacher incentives in the third world. Teaching and Teacher Education, 1993; 9 (3), 301-316.

[4] Edmond N \& Hayler M. On either side of the teacher: perspectives on professionalism in education. Journal of Education for Teaching, 2013; 39 (2), 209-221.

[5] Firestone WA. Teacher evaluation policy and conflicting theories of motivation. Educational Researcher, 2014; 43 (2), 100-107.

[6] Fryer RG. Teacher incentives and student achievements: Evidence from New York City public schools. Journal of Labor Economics, 2013; 31 (2), 373-407.

[7] Goodman SF \& Turner LJ. The design of teacher incentive pay and educational outcomes: Evidence from the New York City bonus program. Journal of Labor Economics, 2013; 31 (2), 409-420.

[8] Fuhrman SH \& O'day JA. Rewards and Reform: Creating Educational Incentives That Work. Jossey-Bass Education Series. 1996. Jossey-Bass Inc., Publishers, 350 Sansome Street, San Francisco, CA 94104.

[9] Chang MC, Shaeffer S, Al-Samarrai S, Ragatz AB, De Ree J $\&$ Stevenson R. Teacher reform in Indonesia: The role of politics and evidence in policymaking. 2013. The World Bank.

[10] Hilton G, Assunção FM \& Niklasson L. Teacher quality, professionalism, and professional development: findings from a European project. Teacher Development, 2013; 17 (4), 431-447.

[11] Nutsa KM. Teacher certification examinations in Georgia: Outcomes and policy implications. In Teacher reforms around the world: Implementations and outcomes (pp. 25-51). 2013. Emerald Group Publishing Limited.

[12] Himmelstein DU, Ariely D \& Woolhandler S. Pay-for-performance: toxic to quality? Insights from behavioral economics. International Journal of Health Services, 2014; 44 (2), 203-214.

[13] Imberman SA \& Lovenheim MF. Incentive strength and teacher productivity: Evidence from a group-based teacher incentive pay system. Review of Economics and Statistics, 2015; 97 (2), 364-386.

[14] Jones MD. Teacher behavior under performance pay 
incentives. Economics of Education Review, 2013; 37, 148-164.

[15] Hulme M \& Quirk-Marku C. Re-making teacher professionalism in England: localism and social responsibility. RASE: Revista de la Asociación de Sociología de la Educación, 2017; 10 (3), 347-362.

[16] Jackson CK, Rockoff JE \& Staiger DO. Teacher effects and teacher-related policies. Annu Rev. Econ., 2014; 6 (1), 801-825.

[17] Ingvarson L \& Rowley G. Quality assurance in teacher education and outcomes: A study of 17 countries. Educational Researcher, 2017; 46 (4), 177-193.

[18] Ingvarson L. Professional certification: Promoting and recognizing successful teaching practices. In Sustaining Teachers' Professional Growth Cambridge Seminar (pp. 1-19). 2013.

[19] Joyce TM \& Mmankoko R. Teacher attitudes, professionalism, and unprofessionalism in relation to school violence. Journal of Sociology and Social Anthropology, 2014; 5 (1), 19-27.

[20] Popkewitz TS \& Lind K. Teacher Incentives as Reforms: Teachers' Work and the Changing Control Mechanization in Education. Teachers College Record, 1989; 90 (4), 575-94.

[21] Sachs J. Teacher professionalism: why are we still talking about it?. Teachers and Teaching, 2016; 22 (4), 413-425.

[22] Hattie J. Visible learning: A synthesis of 800+ meta-analyses on achievement. Abingdon: Routledge. 2009.

[23] Chetty R, Friedman JN \& Rockoff JE. Measuring the impacts of teachers II: Teacher value-added and student outcomes in adulthood. American Economic Review, 2014; 104, 2633-2679.

[24] Joyce B, Weil M \& Calhoun E. Models of teaching. (2003).

[25] Jazuli A, Sulthon PS \& Kuswandi D. Improving conceptual understanding and problem-solving in mathematics through a contextual learning strategy, Global Journal of Engineering Education, 2017, 19 (1), 49-52.

[26] Zakaria E, Yaakob MJ, Maat SM \& Adnan M. Conceptual knowledge and mathematics achievement of matriculation students. Procedia-Social and Behavioral Sciences, 2010; 9 , 1020-1024.

[27] Carlson MP. A cross-sectional investigation of the development of the function concept. In Schoenfield, AH (Ed) Research in collegiate mathematics education III. pp. 114-162. Providence Rhode Island: American Mathematical Society, 1998.

[28] Chappell KK \& Killpatrick K. Effects of concept-based instruction on students' conceptual understanding and procedural knowledge of Calculus. PRIMUS, 2003; 13 (1), 17-37.

[29] Mansor R., Halim L \& Osman K. Teachers 'knowledge that promotes students' conceptual understanding. Procedia-Social and Behavioral Sciences, 2010; 9, 1835-1839.

[30] Thompson BC, Mazer JP \& Flood Grady E. The changing nature of parent-teacher communication: Mode selection in the smartphone era. Communication Education, 2015; 64 (2), 187-207.

[31] Roberts BW \& DelVecchio WF. The rank-order consistency of personality traits from childhood to old age: A quantitative review of longitudinal studies. Psychological Bulletin, 2000; 126, 3 - 25.

[32] Roberts BW \& Jackson JJ. Sociogenomic personality psychology. Journal of Personality, 2008; 76, 1523 - 1544.

[33] Kim LE, Dar-Nimrod I \& MacCann C. Teacher personality and teacher effectiveness in secondary school: Personality predicts teacher support and student self-efficacy but not academic achievement. Journal of Educational Psychology, 2018; 110 (3), 309-323.

[34] Alexander LS. The Effect of Secondary Teacher Personality on Educational Empowerment. Dissertation. Walden University. 2017.

[35] Roberts BW, Luo J, Briley DA, Chow PI, Su R \& Hill PL. A systematic review of personality trait change through intervention. Psychological Bulletin, 201 7; 143, 117 - 141

[36] Kim LE \& MacCann C. What are students' ideal university instructor personality? An investigation of absolute and relative personality preferences. Personality and Individual Differences, 2016; 102,190 - 203. 